June 2015

\title{
Characterization of in-hospital cardiac arrest in adult patients at a tertiary hospital in Kenya
}

Benjamin Wachira

Aga Khan University, benjamin.wachira@aku.edu

Follow this and additional works at: http://ecommons.aku.edu/eastafrica_fhs_mc_intern_med Part of the Emergency Medicine Commons

\section{Recommended Citation}

Wachira, B. (2015). Characterization of in-hospital cardiac arrest in adult patients at a tertiary hospital in Kenya. African Journal of Emergency Medicine, 5(2), 70-74.

Available at: http://ecommons.aku.edu/eastafrica_fhs_mc_intern_med/35 
African Federation for Emergency Medicine

African Journal of Emergency Medicine

AfJEM

www.afjem.com

www.sciencedirect.com

\title{
ORIGINAL RESEARCH ARTICLES
}

\section{Characterization of in-hospital cardiac arrest in adult patients at a tertiary hospital in Kenya}

\section{Caractérisation de l'arrêt cardiaque à l'hôpital chez les patients adultes dans un hôpital tertiaire au Kenya}

\author{
Benjamin W. Wachira ${ }^{\mathrm{a}, *}$, Matthew D. Tyler ${ }^{\mathrm{b}}$ \\ ${ }^{a}$ Accident \& Emergency Department, Aga Khan University Hospital, Nairobi, Kenya \\ b Boston Medical Center, Boston, MA, United States
}

Received 29 July 2014; revised 23 September 2014; accepted 3 October 2014; available online 29 November 2014

\begin{abstract}
Background: In-hospital cardiac arrest (IHCA) is defined as a cardiac arrest that occurs in a hospital and for which resuscitation is attempted. Despite the increased morbidity and mortality, IHCA incidence and outcomes remain largely unknown especially in sub-Saharan Africa. This study describes the baseline characteristics, prearrest physiological parameters and the rate of survival to hospital discharge of adult patients with an IHCA at a tertiary hospital in Kenya.

Methods: This was a retrospective chart review. Data on patient characteristics, pre-arrest physiological parameters and discharge condition were collected on all patients 18 years of age or older with an IHCA at the Aga Khan University Hospital, Nairobi, from January 2013 to December 2013.

Results: The main study population comprised 108 patients. The mean age was $59.3 \pm 18.4$ years and $63(58.3 \%)$ patients were men. The initial rhythm post cardiacarrest was pulseless electrical activity $(41.7 \%)$ or asystole $(35.2 \%)$ in the majority of cases. Hypertension (43.5\%), septicaemia $(40.7 \%)$, renal insufficiency $(30.6 \%)$, diabetes mellitus $(25.9 \%)$ and pneumonia $(15.7 \%)$ were the leading pre-existing conditions in the patients. A Modified Early Warning Score (MEWS) of 5 or more was reached in $56(67.5 \%, n=83)$ patients before the cardiac arrest. The rate of survival to hospital discharge was $11.1 \%$. All the patients who survived to hospital discharge had a good neurological outcome.

Conclusions: Early identification of warning signs that precede many in-hospital arrests may enable institution of treatment to prevent patient deterioration. Local hospitals should be encouraged to provide patients with resuscitation services and equipment in line with evidence-based programmes.
\end{abstract}

Contexte: L'arrêt cardiaque à l'hôpital (IHCA, In-hospital cardiac arrest) se définit par un arrêt cardiaque ayant lieu dans un hôpital et pour lequel on tente une réanimation. Malgré sa morbidité et sa mortalité croissantes, l'incidence de l'IHCA et ses résultats restent très méconnus, en particulier en Afrique sub-saharienne. Cette étude décrit les caractéristiques fondamentales, les paramètres physiologiques précédant l'arrêt et le taux de survie à la sortie de l'hôpital des patients adultes ayant subi un IHCA dans un hôpital tertiaire eu Kenya.

Méthodes: Il a été procédé à un examen rétrospectif des dossiers. Les données sur les caractéristiques des patients, les paramètres physiologiques précédant l'arrêt et l'état à la sortie ont été recueillies pour tous les patients de plus de 18 ans ayant subi un IHCA à l'Hôpital Universitaire Aga Khan de Nairobi, de janvier 2013 à décembre 2013 .

Résultat: La population de l'étude principale était de 108 patients. L'âge moyen était de 59,3 $\pm 18,4$ ans et 63 (58,3\%) patients étaient des hommes. Dans la majorité des cas, le rythme initial suivant l'arrêt cardiaque était une activité électrique sans pouls $(41,7 \%)$ ou une asystole (35,2\%). Les affections préexistantes les plus courantes chez les patients étaient l'hypertension (43,5\%), la septicémie (40,7\%), l'insuffisance rénale (30,6\%), le diabète sucré $(25,9 \%)$ et la pneumonie (15,7\%). Un Score d'alerte précoce modifié (MEWS, Modified Early Warning Score) de 5 ou plus a été atteint chez $56(67,5 \%, n=83)$ patients avant l'arrêt cardiaque. Le taux de survie à la sortie de l'hôpital était de $11,1 \%$. Tous les patients qui ont survécu à la sortie de l'hôpital présentaient de bons résultats neurologiques.

Conclusions: L'identification précoce des signes d'alerte précédant bon nombre d'arrêts cardiaques à l'hôpital peut permettre l'instauration d'un traitement visant à prévenir la dégradation de l'état de patient. Les hôpitaux locaux devraient être encouragés à fournir aux patients des services et des équipements de réanimation conformément aux programmes fondés sur des faits probants.

\section{African relevance}

- The article demonstrates the possibility of developing hospital resuscitation teams in health facilities in Africa.

\footnotetext{
* Correspondence to Benjamin W. Wachira. benjamin.wachira@aku.edu Peer review under responsibility of African Federation for Emergency Medicine.

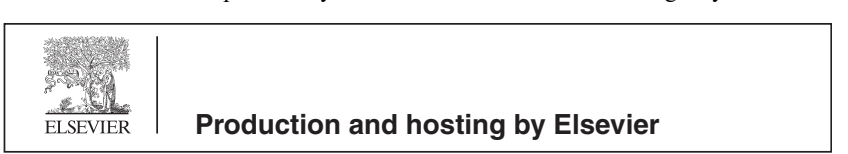

- Development of systems to identify early warning signs that precede many in-hospital arrests in Africa may enable introduction of treatment to prevent patient deterioration.

- There are gaps in current local morbidity and mortality data highlighting a need for research into the causes of in-hospital cardiac arrests.

\section{Introduction}

Cardiac arrest is defined as the lack of a palpable central pulse, apnoea, and unresponsiveness. ${ }^{1}$ In-hospital cardiac arrest 
(IHCA) is defined as a cardiac arrest that occurs in a hospital (whether the patient is admitted or not) and for which resuscitation is attempted with chest compressions, defibrillation, or both. $^{2}$ Despite the increased morbidity and mortality, IHCA incidence and outcomes remain largely unknown especially in sub-Saharan Africa.

Majority of the studies have focused on out-of-hospital cardiac arrest (OHCA) with a limited number of studies reporting on the incidence, patient characteristics and outcomes after IHCA. Single-institution studies have reported hospital-wide incidence rates of adult IHCA ranging from 3.8 to 13.1 per 1000 admissions. $^{3,4}$ These large variations are primarily due to the absence of standardized data sets containing uniform definitions and reliable data abstraction across hospitals. In an effort to solve this problem, the American Heart Association (AHA) recently published recommendations aimed at measuring and optimizing outcomes after in-hospital cardiac arrest (IHCA). ${ }^{2}$

Survival rates among patients with OHCAs have increased in the last decade due to improvements in resuscitation care. ${ }^{5-8}$ It is commonly assumed that advances in OHCA care are directly applicable to the epidemiology and treatment of IHCA. Recent data from the Get with the Guidelines (GWTG)-Resuscitation registry based in the United States showed a rate of survival to hospital discharge for IHCA of $17.0 \%{ }^{9}$ Whether similar rates are observable in other regions remains largely unknown due to the different causes and burden of chronic illnesses that contribute to IHCA epidemiology, team configuration, and access to resources, especially in subSaharan Africa.

Kenya is located on the equator in the eastern part of Africa. It has a population of over 38 million people; Nairobi, the capital, has a population of more than three million people. ${ }^{10}$ The leading causes of death and disability in Kenya are shown in Table $1 .^{11}$

The Aga Khan University Hospital, Nairobi (AKUH, N), is a regional tertiary referral university hospital that provides secondary and tertiary level health care services in Nairobi. It has over 300 beds with a 24-h Emergency Centre (EC), 11-bed High Dependency Unit (HDU) and a 20-bed Intensive Care Unit (ICU). The Code Blue Team is the dedicated hospital emergency response team constituted of nurses and doctors from the EC and ICU. The team handles all in-hospital cardiac arrests. It is activated by a single four-digit number from any telephone extension in the hospital, $24 \mathrm{~h}$ a day, seven days a week, in the event of a cardiac arrest within the hospital premises. All team members are trained in basic and advanced life support according to the American Heart Association guidelines. During the resuscitation, a pre-designated member of the Code Blue Team records all the events of the resuscitation on a specially designed resuscitation form.

This study aimed to: (i) describe the baseline characteristics and pre-arrest physiological parameters of adult patients with an IHCA at a tertiary hospital in Kenya; and (ii) determine their rate of survival to hospital discharge using the recently published recommendations from the AHA. The hope is that an improved understanding of the scope of this problem will help guide future research and implementation of strategies that will benefit healthcare delivery that pertains to IHCA.

\section{Methods}

This was a retrospective chart review. Resuscitation forms from January 1, 2013, through December 31, 2013 were used to identify all patients 18 years of age or older with an IHCA at the Aga Khan University Hospital, Nairobi (Fig. 1). Only the index pulseless cardiac arrest for each admission was included in the study.

The study sample was comprised of 108 patients. The study was approved by the Aga Khan University Faculty of Health Sciences East Africa research ethics committee (2014/REC-24).

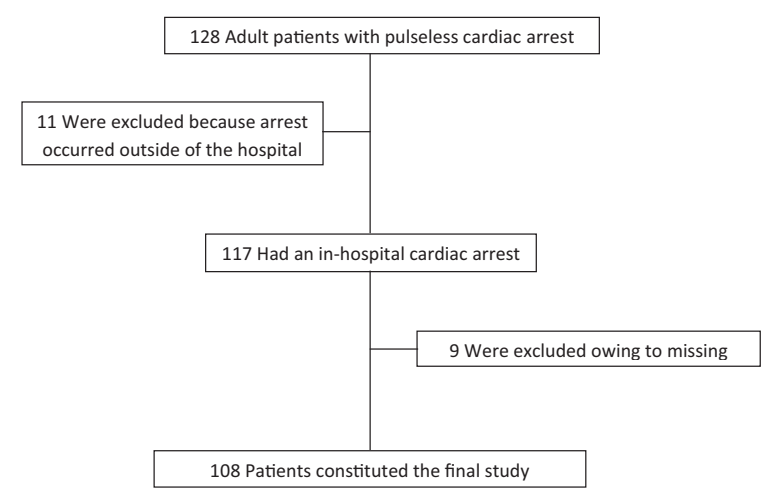

Figure 1 Study cohort.

Table 1 Leading causes of deaths and disability in Kenya. ${ }^{11}$

\begin{tabular}{|c|c|c|c|c|c|}
\hline \multicolumn{3}{|c|}{ Causes of death } & \multicolumn{3}{|c|}{ Causes of DALYs ${ }^{\mathrm{a}}$} \\
\hline Rank & Disease or injury & $\%$ total deaths & Rank & Disease or injury & $\%$ total DALY's \\
\hline 1 & HIV/AIDS & 29.3 & 1 & HIV/AIDS & 24.7 \\
\hline 2 & Conditions arising during perinatal period & 9.0 & 2 & Conditions arising during perinatal period & 10.7 \\
\hline 3 & Lower respiratory infections & 8.1 & 3 & Malaria & 7.2 \\
\hline 4 & Tuberculosis & 6.3 & 4 & Lower respiratory infections & 7.1 \\
\hline 5 & Diarrhoeal diseases & 6.0 & 5 & Diarrhoeal diseases & 6.0 \\
\hline 6 & Malaria & 5.8 & 6 & Tuberculosis & 4.8 \\
\hline 7 & Cerebrovascular disease & 3.3 & 7 & Road traffic accidents & 2.0 \\
\hline 8 & Ischaemic heart disease & 2.8 & 8 & Congenital anomalies & 1.7 \\
\hline 9 & Road traffic accidents & 1.9 & 9 & Violence & 1.6 \\
\hline 10 & Violence & 1.6 & 10 & Unipolar depressive disorder & 1.5 \\
\hline
\end{tabular}

${ }^{\text {a }}$ DALYs $=$ Disability Adjusted Life Years - Time lost due to incapacity arising from ill health. 
Table 2 Modified Early Warning Score. ${ }^{\mathrm{a}, 13}$

\begin{tabular}{|c|c|c|c|c|c|c|c|}
\hline \multicolumn{8}{|l|}{ Individual component scores } \\
\hline Parameter & 3 & 2 & 1 & 0 & 1 & 2 & 3 \\
\hline Systolic blood pressure (mmHg) & $\leqslant 70$ & $71-80$ & $81-100$ & $101-199$ & & $\geqslant 200$ & \\
\hline Heart rate $(\mathrm{bpm})$ & & $\leqslant 40$ & $41-50$ & $51-100$ & $101-110$ & $111-129$ & $\geqslant 130$ \\
\hline Respiratory rate (bpm) & & $<9$ & & $9-14$ & $15-20$ & $21-29$ & $\geqslant 30$ \\
\hline Temperature $\left({ }^{\circ} \mathrm{C}\right)$ & & $<35$ & $35-38.4$ & & & $\geqslant 38.5$ & \\
\hline AVPU score & & & & Alert & Reacting to Voice & Reacting to Pain & Unresponsive \\
\hline
\end{tabular}

${ }^{\text {a }}$ Modified Early Warning Score (MEWS) is calculated as the sum of the individual component scores.

Study data were filled in directly from the resuscitation forms and the patients' records onto the data sheets. Data collected on each patient included: age and sex; date and time of cardiac arrest; location of cardiac arrest; time to Code Blue Team arrival; first documented pulseless rhythm; duration of resuscitation; return of spontaneous circulation (ROSC) (defined as $>20$ min of sustained ROSC); pre-existing conditions at time of cardiac arrest; discharge condition and cerebral-performance category (CPC) scores at admission and at discharge. ${ }^{12}$ A CPC score of 1 denotes mild or no neurologic disability, 2: moderate neurologic disability, 3: severe neurologic disability, 4: coma or vegetative state, and 5 brain death.

Data were also collected on the patients' physiologic parameters including heart rate, systolic blood pressure, respiratory rate, temperature and AVPU score (A for 'alert', V for 'reacting to vocal stimuli', $\mathrm{P}$ for 'reacting to pain', $\mathrm{U}$ for 'Unconscious') during the $4 \mathrm{~h}$ before the cardiac arrest. Only the last four measurements taken during this period were collected. The measurements were used to calculate a Modified Early Warning Score (MEWS) (Table 2). ${ }^{13}$ MEWS is a tool that has been validated for bedside evaluation to determine the severity of illness of a patient based on five physiological parameters: systolic blood pressure, pulse rate, respiratory rate, temperature and AVPU score. A score of five or more has statistically been linked to increased likelihood of death or admission to an intensive care unit. ${ }^{14}$

All statistical analyses were conducted using Microsoft Office Excel 2014 software. For continuous variables, the mean and the standard deviation of the mean (SD) was calculated. Frequencies in percent were determined for all categorical variables.

\section{Results}

\section{Patient characteristics}

Table 3 summarizes the characteristics of IHCA among the study population.

Ninety-three $(86.1 \%)$ patients had only one arrest during the same admission; however, 14 (12.9\%) had two arrests, and one patient $(1 \%)$ had three arrests.

\section{Physiological parameters before the cardiac arrest}

Physiological parameters taken during the $4 \mathrm{~h}$ before the cardiac arrest were available for $101(93.5 \%, n=108)$ patients. Each complete set of physiological data collected during the $4 \mathrm{~h}$ before the cardiac arrest was used to calculate a MEWS;
$77 \%$ of patients had complete data sets. A MEWS of 5 or more was reached in $56(67.5 \%, n=83)$ patients during the four hours before the cardiac arrest. Fifty-four $(65.1 \%$, $n=83$ ) patients had more than one MEWS calculated during the $4 \mathrm{~h}$ before the cardiac arrest. Thirty-three $(61.1 \%, n=54)$

Table 3 Baseline characteristics of patients with an in-hospital cardiac arrest.

\begin{tabular}{|c|c|}
\hline \multicolumn{2}{|l|}{ Characteristic $(n=108)$} \\
\hline Demographics & No. $(\%)$ \\
\hline Age (years) & $59.3 \pm 18.4$ \\
\hline Male sex & $63(58.3)$ \\
\hline Female sex & $45(41.7)$ \\
\hline \multicolumn{2}{|l|}{ Cardiac arrest } \\
\hline Initial cardiac-arrest rhythm & No. $(\%)$ \\
\hline Pulseless electrical activity (PEA) & $45(41.7)$ \\
\hline Asystole & $38(35.2)$ \\
\hline Unknown rhythm by documentation & $11(10.2)$ \\
\hline Pulseless ventricular tachycardia (VT) & $8(7.4)$ \\
\hline Ventricular fibrillation (VF) & $6(5.6)$ \\
\hline \multicolumn{2}{|l|}{ Hospital location of arrest } \\
\hline Intensive care unit (ICU) & $43(39.8)$ \\
\hline High dependency unit (HDU) & $23(21.3)$ \\
\hline Coronary care unit (CCU) & $14(13.0)$ \\
\hline General in-patient area (wards) & $14(13.0)$ \\
\hline Emergency centre (EC) & $4(3.7)$ \\
\hline Renal unit & $4(3.7)$ \\
\hline Catheterization lab & $3(2.8)$ \\
\hline Operating room (theatres) & $2(1.9)$ \\
\hline Out-patient clinic & $1(0.9)$ \\
\hline Arrest at night (11 p.m. to 7 a.m.) & $33(30.6)$ \\
\hline Arrest on weekend & $40(37)$ \\
\hline Average Code Blue Team response time (seconds) ${ }^{\mathrm{a}}$ & $164 \pm 135$ \\
\hline Pre-existing conditions & No. $(\%)$ \\
\hline Hypertension & $47(43.5)$ \\
\hline Septicaemia & $44(40.7)$ \\
\hline Renal insufficiency & $33(30.6)$ \\
\hline Diabetes mellitus & $28(25.9)$ \\
\hline Pneumonia & $17(15.7)$ \\
\hline HIV/AIDS & $15(13.9)$ \\
\hline Metastatic cancer & $15(13.9)$ \\
\hline Previous heart failure & $12(11.1)$ \\
\hline Myocardial infarction, current admission & $10(9.3)$ \\
\hline Previous myocardial infarction & $9(8.3)$ \\
\hline Major Trauma & $9(8.3)$ \\
\hline Acute stroke & $5(4.6)$ \\
\hline Hepatic insufficiency & $4(3.7)$ \\
\hline Heart failure, current admission & $2(1.9)$ \\
\hline
\end{tabular}

${ }^{\text {a }}$ This is the average response time to all areas except the Emergency Centre and the Intensive Care Unit. 
Table 4 Outcomes of in-hospital cardiac arrest by first documented pulseless rhythm. ${ }^{\text {a,b }}$

\begin{tabular}{|c|c|c|c|c|}
\hline & $\begin{array}{l}\mathrm{VF}^{\mathrm{c}} \text { or Pulseless } \mathrm{VT}^{\mathrm{c}} \\
n=14\end{array}$ & $\begin{array}{l}\text { Asystole } \\
n=38\end{array}$ & $\begin{array}{l}\text { PEA }^{\mathrm{c}} \\
n=45\end{array}$ & $\begin{array}{l}\text { Unknown rhythm } \\
n=11\end{array}$ \\
\hline $\operatorname{ROSC}^{\mathrm{c}}>20 \mathrm{~min}$ & $6(42.9)$ & $10(26.3)$ & $19(42.2)$ & $4(36.3)$ \\
\hline Survival to discharge & $1(7.1)$ & $3(7.9)$ & $6(13.3)$ & $2(18.2)$ \\
\hline \multicolumn{5}{|l|}{ Neurological outcome } \\
\hline Good $^{\mathrm{e}}$ & $1(7.1)$ & $3(7.9)$ & $6(13.3)$ & $2(18.2)$ \\
\hline Poor & $0(0.0)$ & $0(0.0)$ & $0(0.0)$ & $0(0.0)$ \\
\hline \multicolumn{5}{|c|}{$\begin{array}{l}\text { a First documented pulseless rhythm was defined as the first electrocardiographic rhythm documented at the time of the cardiac arrest. } \\
\text { b Values are number (\%) of patients. } \\
\text { c VF: ventricular fibrillation; VT: ventricular tachycardia; PEA: pulseless electrical activity; ROSC: return of spontaneous circulation. } \\
\text { d } \text { Unknown rhythm by documentation. } \\
\text { e Good neurological outcome was defined as cerebral performance category (CPC) } 1 \text { or } 2 \text { or no change from baseline CPC. }\end{array}$} \\
\hline
\end{tabular}

patients demonstrated a deterioration in their MEWS at one point during the $4 \mathrm{~h}$ before the cardiac arrest.

\section{Survival to hospital discharge}

The rate of survival to hospital discharge was $11.1 \%$ (12 of 108 patients). Table 4 summarizes outcomes for IHCA patients as a function of the first pulseless rhythm obtained at the time of the cardiac arrest.

\section{Discussion}

This study is the first comprehensive standardized characterization of IHCA in Kenya. These results will help inform the development and advancement of local systems for IHCA care.

\section{Patient characteristics}

The mean age of the patients was $59.3 \pm 18.4$ years. This may be related to the latest WHO data, which indicates that the current total life expectancy in Kenya is 59.7 years. ${ }^{15}$ The initial rhythm at the time of the cardiac arrest was PEA or asystole in majority of the patients. Similar studies on IHCA have demonstrated similar findings ${ }^{9,16,17}$ which contrast studies on OHCAs, which typically report a higher prevalence of $\mathrm{VF} /$ VT rhythms. ${ }^{18}$ The differences in pathophysiology partially explains the lower prevalence of $\mathrm{VF} / \mathrm{VT}$ rhythms in IHCA in comparison to OHCA: hypoxia or hypotension which frequently precipitate IHCA, ${ }^{17,19}$ are more likely to cause PEA or asystole than VF/VT. Conversely, when ischemia is the precipitating cause of cardiac arrest, as often occurs in OHCA, $\mathrm{VF} / \mathrm{VT}$ rhythms are more common. The list of pre-existing conditions of patients who had an IHCA demonstrates the rising burden of non-communicable diseases (NCDs) in Kenya. NCDs, including cardiovascular diseases and metastatic cancer, pose a growing health challenge for Kenya and other sub-Saharan Africa countries which are still grappling with high burdens of communicable diseases and HIV/AIDS; a rise in road traffic injuries further compounds the situation. ${ }^{20}$ Though pre-arrest variables such as sepsis, renal failure, metastatic cancer and stroke are associated with worse prognosis after IHCA, they cannot completely explain the cardiac arrest outcomes. ${ }^{21-23}$

\section{Physiological parameters before the cardiac arrest}

A MEWS of five or more is linked to increased likelihood of death or admission to an ICU. ${ }^{14}$ This previously reported finding was clearly demonstrated in this study as well; a majority of the patients in the study who eventually had an IHCA had a MEWS of five or more at one point during the $4 \mathrm{~h}$ before the cardiac arrest. Patient deterioration was also noted during the $4 \mathrm{~h}$ before the arrest in up to $61.1 \%$ of cases. Greater emphasis should be placed on the need to regularly calculate the MEWS for all patients admitted in the hospital to identify those patients with an increased likelihood of death. Interventions by trained in-hospital staff should be instituted immediately clinical deterioration is detected to try and prevent IHCA.

\section{Survival to hospital discharge}

The rate of survival to hospital discharge was lower than those observed in similar studies from North America $(11 \%$ vs. $17 \%) .^{9}$ Differences in the causes and burden of comorbidities in the two populations that contribute to IHCA epidemiology may partially explain this finding. More research is needed to determine the specific factors that are responsible for the differences in survival after cardiac arrest between the two populations. All the survivors-to-hospital discharge had a good neurological outcome - defined as cerebral performance category (CPC) of 1 or 2 or no change from baseline CPC. This finding is in keeping with the majority of papers that also report relatively good functional outcomes in survivors from IHCA. ${ }^{9,17,24}$ Therapeutic hypothermia, though recommended for comatose adult patients with ROSC after IHCA of any initial rhythm, ${ }^{25}$ was not instituted due to lack of resources but this did not seem to influence our findings.

\section{Limitations}

Being a retrospective chart review, the study was subject to limitations and biases, including missing data; collection of nonrandomized data; and as this was one hospital, the population may not be representative of the whole country. Assessment of the quality of resuscitation was not part of the scope of this study. 


\section{Conclusions}

This is the first study to characterize in-hospital cardiac arrest in Kenya. It provides important information on patients with IHCA and may have implications for the development of local systems to advance IHCA care. Early identification of warning signs that precede many in-hospital arrests may enable institution of treatment to prevent patient deterioration. Local hospitals should be encouraged to provide patients with resuscitation services and equipment in line with evidencebased programmes. Resuscitation outcomes should subsequently be collected, regularly reviewed, and published to provide more useful information for improving outcomes after in-hospital cardiac arrest.

\section{Conflict of interest}

The authors declare no conflict of interest.

\section{Acknowledgements}

The authors wish to thank Dr. Jeremiah Njenga who assisted with the data collection and Dr. Gabrielle Jacquet, Gregory Bell and Gerene Denning, who reviewed the final manuscript.

\section{References}

1. Jacobs I, Nadkarni V, Bahr J, et al. Cardiac arrest and cardiopulmonary resuscitation outcome reports: update and simplification of the Utstein templates for resuscitation registries: a statement for healthcare professionals from a task force of the International Liaison Committee on Resuscitation (American Heart Association, European Resuscitation Council, Australian Resuscitation Council, New Zealand Resuscitation Council, Heart and Stroke Foundation of Canada, InterAmerican Heart Foundation, Resuscitation Councils of Southern Africa). Circulation 2004;110:3385-97.

2. Morrison LJ, Neumar RW, Zimmerman JL, et al. Strategies for improving survival after in-hospital cardiac arrest in the United States: 2013 consensus recommendations: a consensus statement from the American Heart Association. Circulation 2013; 127:1538-63.

3. Hodgetts TJ, Kenward G, Vlackonikolis I, et al. Incidence, location and reasons for avoidable in-hospital cardiac arrest in a district general hospital. Resuscitation 2002;54:115-23.

4. Jones-Crawford JL, Parish DC, Smith BE, et al. Resuscitation in the hospital: circadian variation of cardiopulmonary arrest. $\mathrm{Am} \mathrm{J}$ Med 2007;120:158-64.

5. Rea TD, Crouthamel M, Eisenberg MS, et al. Temporal patterns in long-term survival after resuscitation from out-of-hospital cardiac arrest. Circulation 2003;108:1196-201.

6. Hinchey PR, Myers JB, Lewis R, et al. Improved out-of-hospital cardiac arrest survival after the sequential implementation of 2005 AHA guidelines for compressions, ventilations, and induced hypothermia: the Wake County experience. Ann Emerg Med 2010;56:348-57.

7. Pell JP, Corstorphine M, McConnachie A, et al. Post-discharge survival following pre-hospital cardiopulmonary arrest due to cardiac aetiology: temporal trends and impact of changes in clinical management. Eur Heart J 2006;27:406-12.

8. Aufderheide TP, Yannopoulos D, Lick CJ, et al. Implementing the 2005 American Heart Association Guidelines improves outcomes after out-of-hospital cardiac arrest. Heart Rhythm 2010;7:1357-62.

9. Girotra S, Nallamothu BK, Spertus JA, et alAmerican Heart Association Get with the Guidelines-Resuscitation Investigators. Trends in survival after in-hospital cardiac arrest. $N$ Engl J Med 2012;367:1912-20.

10. Kenya National Bureau of Statistics (KNBS). 2009 population and housing census. Kenya National Bureau of Statistics (KNBS). $<$ http://www.knbs.or.ke/index.php?option $=$ com_content\&view $=$ article\&id $=152$ :population\&catid $=112 \&$ Itemid $=638>; \quad 2013$ accessed 14 May 2014.

11. Government of Kenya. Review of the Kenya health policy framework, 1994-2010; 2010.

12. Jennett B, Bond M. Assessment of outcome after severe brain damage. Lancet 1975;1:480-4.

13. Morgan RJM, Williams F, Wright MM. An Early Warning Scoring system for detecting developing critical illness. Clin Intensive Care 1997;8:100.

14. Subbe CP, Kruger M, Rutherford $\mathrm{P}$, et al. Validation of a modified Early Warning Score in medical admissions. $Q J$ Med 2001;94:507-10.

15. World Health Organization (WHO). Life expectancy: Life expectancy Data by country. WHO. < http://apps.who.int/gho/data/node.main.688 >; 2013 accessed 14 May 2014.

16. Sandroni C, Cavallaro F, Ferro G, et al. A survey of the inhospital response to cardiac arrest on general wards in the hospitals of Rome. Resuscitation 2003;56:41-7.

17. Peberdy MA, Kaye W, Ornato JP, et al. Cardiopulmonary resuscitation of adults in the hospital: a report of 14720 cardiac arrests from the National Registry of Cardiopulmonary Resuscitation. Resuscitation 2003;58:297-308.

18. Bayes de Luna A, Coumel P, Leclercq JF. Ambulatory sudden cardiac death: mechanisms of production of fatal arrhythmia on the basis of data from 157 cases. Am Heart $J$ 1989;117:151-9.

19. Kause J, Smith G, Prytherch D, et al. A comparison of antecedents to cardiac arrests, deaths and emergency intensive care admissions in Australia and New Zealand, and the United Kingdom - the ACADEMIA study. Resuscitation 2004;62:275-82.

20. Institute for Health Metrics and Evaluation. The global burden of disease: generating evidence, guiding policy. Seattle, WA: IHME; 2013.

21. George Jr AL, Folk III BP, Crecelius PL, et al. Pre-arrest morbidity and other correlates of survival after in-hospital cardiopulmonary arrest. Am J Med 1989;87:28-34.

22. Cohn EB, Lefevre F, Yarnold PR, et al. Predicting survival from in-hospital CPR: meta-analysis and validation of a prediction model. J Gen Intern Med 1993;8:347-53.

23. Cooper S, Janghorbani M, Cooper G. A decade of in-hospital resuscitation: outcomes and prediction of survival. Resuscitation 2006; 68:231-7.

24. De Vos R, de Haes HC, Koster RW, et al. Quality of survival after cardiopulmonary resuscitation. Arch Intern Med 1999;159:249-54.

25. Peberdy MA, Callaway CW, Neumar RW, et al. Part 9: postcardiac arrest care: 2010 American Heart Association Guidelines for Cardiopulmonary Resuscitation and Emergency Cardiovascular Care published corrections appear in Circulation. 2011;123:e237 and Circulation. 2011;124:e403. Circulation 2010;122(Suppl. 3):S768-86. 